\title{
Silagem de grãos de milho, com adição de soja: estabilidade aeróbia e desempenho de vacas leiteiras
}

\author{
High moisture corn silage with added soybeans grains: aerobic stability, ruminal \\ disappearance and performance of dairy cows
}

\author{
TRES, Tamara Tais ${ }^{1 *}$; JOBIM, Clóves Cabreira ${ }^{1}$; ROSSI, Robson Marcelo ${ }^{2}$; SILVA, \\ Michele Simili da ${ }^{1}$; POPPI, Edson Carlos ${ }^{3}$
}

\author{
${ }^{1}$ Universidade Estadual de Maringá, Programa de Pós Graduação em Zootecnia, Maringá, Paraná, Brasil. \\ ${ }^{2}$ Universidade Estadual de Maringá, Departamento de Estatística, Maringá, Paraná, Brasil. \\ ${ }^{3}$ Zootecnista, Lallemand Animal Nutrition. Maringá, Paraná, Brasil. \\ *Endereço para correspondência: tamaratais@zootecnista.com.br, ccjobim@uem.br
}

\section{RESUMO}

Objetivou-se avaliar o efeito do uso de aditivo microbiano e de uréia na composição química, digestibilidade in vitro, no desaparecimento ruminal, e na estabilidade aeróbia de silagens de grãos úmidos de milho com adição de soja crua. Um segundo ensaio foi conduzido com o objetivo de avaliar a substituição do concentrado comercial por silagem de grãos de milho com adição de $20 \%$ de soja crua na produção e composição do leite de vacas holandesas. Para a avaliação das silagens foram feitos mini silos de pvc arranjados em delineamento inteiramente casualizado com três tratamentos (silagem de grãos úmidos de milho + $20 \%$ de soja crua; silagem de grãos úmidos de milho $+20 \%$ de soja crua + inoculante microbiano e silagem de grãos úmidos de milho $+20 \%$ de soja crua $+1,4 \%$ de ureia) e quatro repetições. As silagens apresentaram-se estáveis no período de 96 horas, com perdas de matéria seca de 3,55, 3,32 e 4,39 para silagens sem aditivos, com a adição de inoculante microbiano e com uréia respectivamente. A adição de uréia diminuiu a taxa de degradação ruminal das silagens de grãos úmidos de milho com adição de soja. Para a avaliação da produção e composição do leite foram utilizadas 20 vacas leiteiras arranjadas em delineamento inteiramente casualizado, com dois tratamentos e dez repetições. Verificou-se que a silagem de grãos de milho com adição de grãos de soja pode ser usada na alimentação de vacas em lactação sem impacto sobre a produção e composição química do leite, mantendo os níveis de produção.

Palavras-chave: aditivos, deterioração aeróbia, digestibilidade in vitro, produção de leite, valor nutricional

\section{SUMMARY}

This study aimed to evaluate the effect of using microbial additive and urea on in vitro digestibility, in ruminal disappearance, and aerobic stability of moisture corn silage with the addition of raw soybeans. The experiment was conducted in a completely randomized design with three treatments (moisture corn grain silage $+20 \%$ of raw soybeans, moisture corn silage + $20 \%$ of raw soybean + microbial inoculant and moisture corn silage $+20 \%$ of raw soybean + $1.4 \%$ of urea) and four replications. Silages showed good aerobic stability, within the period of 96 hours, with few losses of dry matter and no consistent variations in the chemical composition. The Urea addition decreased the rate of ruminal degradation of the moisture corn silage with the addition of soybean. A second trial was conducted to evaluate the replacement of commercial concentrate by moisture corn silage with the addition of $20 \%$ of crude soybean, 20 dairy cows were used and arranged in a completely randomized design with two treatments and ten replicates. It was found that the moisture corn silage with added soybeans can be used in diets for lactating cows, in replacement of the commercial concentrate, with no impact on the production and chemical composition of the milk, maintaining production levels.

Keywords: additive, aerobic deterioration, in vitro digestibility, milk production, nutritive value 


\section{INTRODUÇ̃̃̃O}

A ensilagem de grãos úmidos de milho consiste na colheita dos grãos do milho logo após a maturação físiológica, ocasião em que se verifica teor de umidade ao redor de 28 a $35 \%$. A silagem de grãos de milho apresenta algumas vantagens como à redução de perdas no campo, liberação antecipada da área cultivada, redução dos custos com secagem dos grãos, além de vantagens em termos nutricionais. Em relação ao valor nutricional destaca-se a alta degradabilidade efetiva da matéria seca e também da proteína bruta, possivelmente devido ao estádio em que o milho foi ensilado, com amido presente em forma mais facilmente degradável quando comparado ao grão seco e, também, em função das fermentações ocorridas no silo (JOBIM et al., 2010a).

A ensilagem de grãos de milho com aditivos que elevem o valor nutricional, especialmente no que se refere ao teor de proteína bruta e energia, desperta interesse, visto que pode disponibilizar ao produtor uma silagem com valor nutricional semelhante aos dos concentrados comerciais (JOBIM et al., 2010a). Trabalhos demonstram resultados positivos na adição de grãos de soja na ensilagem de grãos úmidos de milho com aumento nos teores de nutrientes sem interferir na qualidade de fermentação dos grãos durante o processo de ensilagem (JOBIM et al., 2008; JOBIM et al., 2010b).

Estabilidade aeróbia é um termo usado para definir a resistência que a massa ensilada oferece a deterioração após ser exposta ao ar (KUNG JUNIOR \& RANJIT, 2001). A deterioração aeróbia das silagens além de causar perdas de matéria seca e de valor nutricional, também pode apresentar efeitos na qualidade higiênica das silagens com risco de proliferação de microrganismos indesejáveis ou patogênicos como os fungos, bacilos, Listeria monocytogenes, dentre outros, podendo acumular suas toxinas na silagem com efeitos negativos na saúde animal e humana (BORREANI \& TABACCO, 2010; CHELI et al., 2013).

Objetivou-se avaliar o efeito dos aditivos na digestibilidade in vitro e no desaparecimento ruminal de silagens de grãos úmidos de milho com soja crua e também as alterações que ocorrem no valor nutricional das silagens durante a deterioração aeróbia. No segundo ensaio objetivou-se avaliar a substituição do concentrado comercial pela silagem de grãos úmidos de milho com adição de soja na produção e composição do leite de vacas.

\section{MATERIAL E MÉTODOS}

O experimento foi realizado no sítio Ipê localizado em Mandaguaçu - PR. Foram avaliados os seguintes tratamentos: silagem de grãos úmidos de milho $+20 \%$ de soja crua (SGMS); silagem de grãos úmidos de milho + $20 \%$ de soja crua + inoculante microbiano a base de Propionibacterium acidipropionici Ma26/4U e Lactobacillus buchneri NCIMB 4788 (Lallemand Animal Nutrition) na dosagem inoculada de 100 mil ufc /grama de forrageira, (SGMSI) e silagem de grãos úmidos de milho $+20 \%$ de soja crua $+1,4 \%$ de uréia (SGMSU). Os tratamentos foram arranjados em delineamento inteiramente casualizado com quatro repetições e suas médias comparadas por meio do teste Tukey a $5 \%$ de probabilidade.

$\mathrm{O}$ milho foi colhido de uma área de 5 ha, cultivada com o híbrido coodetecCD397YH. A colheita foi efetuada na 
fase de maturação fisiológica, ocasião em que os grãos apresentavam em torno de $65 \%$ de matéria seca. Os grãos de milho foram triturados em peneira de $10 \mathrm{~mm}$, juntamente com os grãos de soja e, posteriormente, foi feita a adição do inoculante microbiano ou uréia $(1,4 \%$ com base na MV). As silagens foram armazenadas em silos experimentais de PVC com $40 \mathrm{~cm}$ de comprimento e $20 \mathrm{~cm}$ de diâmetro, estimando-se uma densidade de $900 \mathrm{~kg} / \mathrm{m}^{3}$. A compactação do material foi realizada com auxílio de bastão de madeira e o fechamento dos silos foi feito com lona plástica preta de polietileno e amarradas com fita adesiva. As silagens foram armazenadas durante 60 dias quando os silos foram abertos para análises.

Para a avaliação da estabilidade aeróbia foram utilizados recipientes de polipropileno, com capacidade de $2 \mathrm{~kg}$, onde foram colocadas as silagens a serem avaliadas, utilizando quatro repetições para cada tratamento. Os recipientes foram vedados com tecido telado (tule), para impedir a entrada de insetos. A estabilidade aeróbia das silagens foi avaliada com base em medidas de temperatura, do $\mathrm{pH}$ e perdas por gases por meio de pesagens. As medidas de temperatura foram realizadas às 8 e 16h, com uso de termômetro digital, modelo Gulterm 1001. As silagens foram expostas a variação da temperatura ambiental (Tabela 1). A leitura dos valores de $\mathrm{pH}$ foi feita com potenciômetro digital uma vez ao dia, às 8h, conforme Cherney \& Cherney (2003). Para determinação das perdas de gases totais, os recipientes foram pesados diariamente às $8 \mathrm{~h}$ de acordo com o descrito por Jobim et al. (2007).

Tabela 1. Dados climáticos durante os 5 dias de estudo de estabilidade aeróbia das silagens

\begin{tabular}{|c|c|c|c|}
\hline \multirow{2}{*}{ Item } & \multicolumn{2}{|c|}{ Temperatura ${ }^{\circ} \mathrm{C}$} & \multirow{2}{*}{ Precipitação mm } \\
\hline & Máxima & Mínima & \\
\hline $1^{\circ} \mathrm{dia}$ & 25 & 9 & 6,4 \\
\hline $2^{\circ} \mathrm{dia}$ & 18 & 9 & 0 \\
\hline $3^{\circ} \mathrm{dia}$ & 21 & 10 & 0 \\
\hline $4^{\circ} \mathrm{dia}$ & 26 & 12 & 0 \\
\hline $5^{\circ} \mathrm{dia}$ & 21 & 15 & 0 \\
\hline
\end{tabular}

Diariamente foram coletadas amostras para análise da composição nutricional das silagens. As amostras foram submetidas à secagem em estufa de ventilação forçada $\left(55^{\circ} \mathrm{C}\right.$ por 72 horas) e, logo após, moídas em peneira com malha de $1 \mathrm{~mm}$ para análise dos teores de matéria seca (MS), proteína bruta $(\mathrm{PB})$, extrato etéreo (EE), matéria mineral $(\mathrm{MM})$ e energia bruta $(\mathrm{EB}) \mathrm{de}$ acordo com métodos descritos por Silva \& Queiroz (2006). Fibra em detergente neutro (FDN) e fibra em detergente ácido (FDA) de acordo com Van Soest \& Robertson (1985).

Para o ensaio de desaparecimento ruminal da matéria seca e da proteína bruta foram utilizados três bois mestiços, com peso vivo médio de $640 \mathrm{~kg}$, portadores de cânula ruminal. Os animais foram adaptados à alimentação durante 10 dias antes da incubação, sendo alimentados duas vezes ao dia, às 8:00 e 16:00h. Foi analisado o desaparecimento da MS e PB nos tempos: 0, 2, 6, 12, 24 horas. As 
amostras foram preparadas de acordo com o método descrito por Vanzant et al. (1998).

A digestibilidade in vitro das silagens foi determinada de acordo com o método de Tilley \& Terry (1963) adaptada para o uso do rúmen artificial, desenvolvido por Ankon ${ }^{\circledR}$, conforme descrito por Holden (1999). O líquido ruminal (inóculo) foi coletado de uma vaca da raça Holandesa com cânula ruminal e com alimentação adaptada durante dez dias antes da coleta. As amostras foram incubadas por $48 \mathrm{~h}$ para a avaliação da digestibilidade "in vitro" da matéria seca. Após este tempo, foi adicionado a pepsina e o $\mathrm{HCl} 6 \mathrm{~N}$ e mantidos por mais $24 \mathrm{~h}$, com o intuito de interromper a atividade microbiana.

Para a avaliação do desempenho de vacas leiteiras o experimento de campo foi conduzido no município de Mandaguaçú$\mathrm{PR}$ e as análises químicas no laboratório de Análise de Alimentos do Departamento de Zootecnia - UEM. Foram avaliadas a produção e a composição do leite de vacas da raça Holandesa, submetidas a tratamentos com base na composição do concentrado (Tabela 2). Foram utilizadas 20 vacas com peso corporal médio de $542 \mathrm{~kg} \mathrm{+-}$ 34.

Tabela 2. Composição química e centesimal dos concentrados em estudo

\begin{tabular}{|c|c|c|}
\hline \multirow{2}{*}{ Ingredientes } & Concentrado 1 & Concentrado 2 \\
\hline & \multicolumn{2}{|c|}{ Composição centesimal } \\
\hline Milho grão- seco & 47 & $\ldots$ \\
\hline Milho grão- silagem & $\ldots$ & 77 \\
\hline Caroço de algodão & 20 & $\ldots$. \\
\hline Farelo de soja & 30 & 20 \\
\hline \multirow[t]{2}{*}{ Mistura mineral } & 3 & 3 \\
\hline & \multicolumn{2}{|c|}{ Composição química $(\% \mathrm{MS})$} \\
\hline MS & 86,18 & 65,21 \\
\hline PB & 23,1 & 22,32 \\
\hline NDT & 79 & 80 \\
\hline FDN & 15,5 & 10,42 \\
\hline FDA & 7,45 & 5,51 \\
\hline${ }^{*} \mathrm{EL}_{1}(\mathrm{Mcal} / \mathrm{kg} \mathrm{MS})$ & 1,82 & 1,84 \\
\hline
\end{tabular}

*Energia líquida para lactação $=\mathrm{EL}_{1}(\mathrm{Mcal} / \mathrm{kg} \mathrm{MS})=(0,0245$ x NDT $)-0,12$.

O milho foi colhido de uma área de 5 ha, cultivada com o híbrido coodetecCD397YH. A colheita foi efetuada na fase de maturação fisiológica, ocasião em que os grãos apresentavam em torno de $65 \%$ de matéria seca. A silagem de grãos foi confeccionada em tambores de 200 litros. No momento do processamento dos grãos de milho (triturados em peneiras de $10 \mathrm{~mm}$ ) para ensilagem adicionou-se $20 \%$ de grãos de soja e foi aplicado o inoculante microbiano a base de Propionibacterium acidipropionici Ma26/4U e Lactobacillus buchneri NCIMB 4788 (Lallemand Animal Nutrition) na dosagem inoculada de 100 mil ufc /grama de forrageira.

Após a ensilagem os silos permaneceram vedados por um período de 70 dias quando foram abertos para uso na alimentação das vacas e retiradas amostras para análises de laboratório.

Os tratamentos foram arranjados em delineamento experimental inteiramente casualizado com dez repetições (vacas), sendo os animais distribuídos de forma homogênea nos tratamentos, com base no período de lactação (DEL médio $=93$ 
+- 22 dias) e produção de leite, assim distribuídos: Conc. 1 = silagem de grãos de milho $+20 \%$ de soja crua, Conc. $2=$ concentrado comercial. Os animais foram mantidos em galpão coberto, com disponibilidade de bebedouros e canzil individual para acesso ao cocho, os alimentos foram fornecidos permitindo sobras de $10 \%$.

Como volumoso os animais receberam silagem de milho, na proporção volumoso:concentrado de 60:40. Durante o período de avaliação do desempenho animal, 80 dias, no período de maio a julho 2010, foram efetuadas duas coletas de leite para análises, as coletas foram realizadas na ordenha da manhã, com amostragem após higienização dos tetos, em recipiente previamente esterilizado, com coleta de jatos de cada teto, e encaminhadas ao Laboratório do Programa de análises do leite da Associação Paranaense de Criadores Bovinos da Raça Holandesa APCBRH, Curitiba - PR, para determinação dos teores de gordura, lactose, proteína e sólidos totais.

Os dados foram submetidos à análise de variância e suas médias comparadas por meio do teste Tukey a 5\% de probabilidade, por intermédio do programa estatístico SAS (STATISTICAL ANALYSIS SYSTEM 1993).

\section{RESULTADOS E DISCUSSÃO}

Garantir uma boa estabilidade aeróbia das silagens é uma tarefa complexa que resulta da interação de vários fatores que influenciam desde o momento do corte da cultura, tempo de ensilagem, microflora epífita até a fase de abertura do silo.

Neste estudo, a maior elevação de temperatura das silagens em relação à temperatura ambiente foi observada com 72 horas de exposição do material ao ar, em que as silagens SGMS, SGMSI, SGMSU apresentaram temperatura média de $15,4^{\circ} \mathrm{C}$, a uma temperatura ambiente de $13,6^{\circ} \mathrm{C}$ (Figura 1). As alterações de temperatura das silagens de forma geral tenderam ao mesmo comportamento da temperatura ambiente, apresentando maiores valores nas observações realizadas a tarde e menores valores nas avaliações no período da manhã. Ressalta-se que nas condições experimentais observaram-se variações diárias de temperatura de 6 a $16^{\circ} \mathrm{C}$ (Tabela 1), o que demonstra que neste estudo mais parâmetros precisam ser considerados para determinação da estabilidade aeróbia das silagens. De acordo com Borreani \& Tabacco (2010), em condições de campo, a temperatura ambiente nem sempre se apresenta como referência apropriada para determinação da deterioração da silagem, visto que em alguns locais observam-se grandes variações sazonais e diárias de temperatura.

Houve efeito do inoculante microbiano $(\mathrm{P}<0,05)$ nos valores de EB das silagens na abertura dos silos (Tabela 3). $\mathrm{O}$ uso da bactéria heterofermentativa Lactobacillus buchneri, por metabolizar quantidades altas de ácido acético inibe o crescimento de leveduras e fungos filamentosos da silagem, consequentemente o consumo de carboidratos solúveis por microrganismos deterioradores também é reduzido, o que pode explicar as maiores concentrações de EB (4557 cal/g) desta silagem. O maior teor de EB também pode ter sido influenciado pelo teor de extrato etéreo que para a SGMSI foi de 9,3\%, já na SGMS foi de $8,6 \%$, enquanto a silagem tratada com uréia apresentou os menores teores de EE (7,5\%) e também os menores valores de EB (4501 cal $/ \mathrm{g})$. 


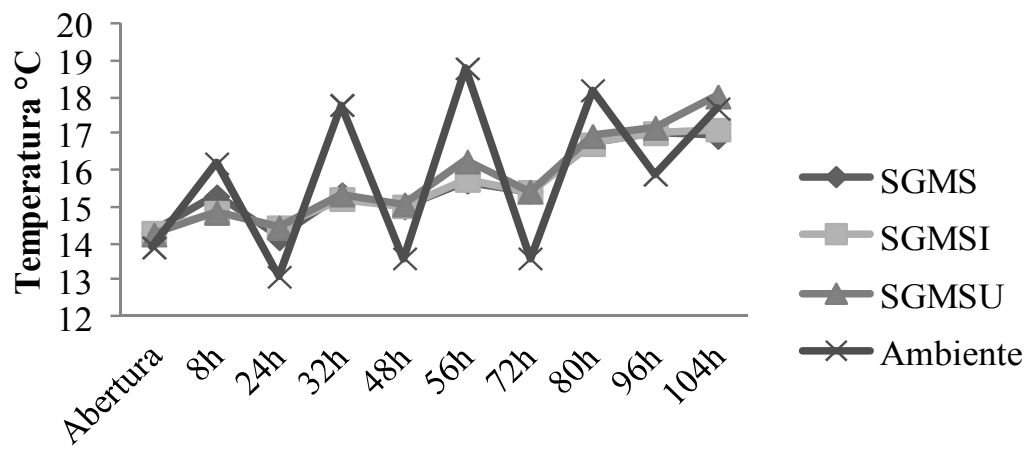

Horas após abertura dos silos

Figura 1. Avaliação da temperatura nos diferentes tempos de exposição das silagens ao ar

Tabela 3. Composição químico-bromatológica das silagens nos diferentes tempos de exposição ao ar

\begin{tabular}{|c|c|c|c|c|c|c|c|}
\hline \multirow{2}{*}{ Item } & Abertura & $8 \mathrm{~h}$ & $24 \mathrm{~h}$ & $48 \mathrm{~h}$ & $72 \mathrm{~h}$ & $96 \mathrm{~h}$ & \multirow[t]{2}{*}{ Médias } \\
\hline & \multicolumn{6}{|c|}{$\mathrm{EB}(\mathrm{cal} / \mathrm{g})$} & \\
\hline SGMS & $4519,91^{\mathrm{bB}}$ & $4419,60^{\mathrm{aC}}$ & $4420,37^{\mathrm{aC}}$ & $4594,76^{\mathrm{aA}}$ & $4555,92^{\mathrm{aAB}}$ & $4572,9^{4 \mathrm{aA}}$ & $4513,92^{\mathrm{a}}$ \\
\hline SGMSI & $4557,02^{\mathrm{aAB}}$ & $4407,59^{\mathrm{aC}}$ & $4445,1454^{\mathrm{aC}}$ & $4590,25^{\mathrm{aA}}$ & $4524,88^{\mathrm{aB}}$ & $4545,66^{\mathrm{aB}}$ & $4511,76^{\mathrm{a}}$ \\
\hline SGMSU & $4501,1181^{\mathrm{bAB}}$ & $4402,23^{\mathrm{aD}}$ & $4431,34^{\mathrm{aCD}}$ & $4533,68^{\mathrm{bA}}$ & $4470,66^{\mathrm{bBC}}$ & $4438,65^{\mathrm{bCD}}$ & $4462,95^{\mathrm{b}}$ \\
\hline \multicolumn{8}{|c|}{ FDN $(\%)$} \\
\hline SGMS & $9,89^{\mathrm{bA}}$ & $9,99^{\mathrm{bA}}$ & $9,50^{\mathrm{bA}}$ & $9,31^{\mathrm{cA}}$ & $10,28^{\mathrm{bA}}$ & $10,38^{\mathrm{bA}}$ & $9,89^{b}$ \\
\hline SGMSI & $10,42^{\mathrm{bAB}}$ & $9,80^{\mathrm{bAB}}$ & $9,28^{\mathrm{bB}}$ & $11,33^{\mathrm{bA}}$ & $10,64^{\mathrm{bAB}}$ & $10,69^{\mathrm{bAB}}$ & $10,36^{\mathrm{b}}$ \\
\hline SGMSU & $12,97^{\mathrm{aAB}}$ & $11,57^{\mathrm{aB}}$ & $11,62^{\mathrm{aB}}$ & $13,36^{\mathrm{aA}}$ & $14,2^{\mathrm{aA}}$ & $13,77^{\mathrm{aA}}$ & $12,91^{\mathrm{a}}$ \\
\hline \multicolumn{8}{|c|}{ FDA $(\%)$} \\
\hline SGMS & $5,31^{\mathrm{bAB}}$ & $4,73^{\mathrm{bB}}$ & $4,91^{\mathrm{bAB}}$ & $5,70^{\mathrm{aA}}$ & $5,09^{\mathrm{aAB}}$ & $4,84^{\mathrm{bAB}}$ & $5,10^{\mathrm{b}}$ \\
\hline SGMSI & $5,51^{\mathrm{bA}}$ & $4,69^{\mathrm{bA}}$ & $4,87^{\mathrm{bA}}$ & $5,29^{\mathrm{aA}}$ & $5,06^{\mathrm{aA}}$ & $4,82^{\mathrm{bA}}$ & $5,04^{b}$ \\
\hline SGMSU & $6,27^{\mathrm{aAB}}$ & $5,71^{\mathrm{aAB}}$ & $6,54^{\mathrm{aA}}$ & $5,42^{\mathrm{aB}}$ & $5,77^{\mathrm{a} A \mathrm{~B}}$ & $6,06^{\mathrm{aAB}}$ & $5,96^{\mathrm{a}}$ \\
\hline \multicolumn{8}{|c|}{ PB $(\%)$} \\
\hline SGMS & $17,32^{\mathrm{bA}}$ & $16,10^{\mathrm{bA}}$ & $16,24^{\mathrm{bA}}$ & $16,65^{\mathrm{bA}}$ & $16,43^{\mathrm{bA}}$ & $16,55^{\mathrm{bA}}$ & $16,55^{\mathrm{c}}$ \\
\hline SGMSI & $18,32^{\mathrm{bA}}$ & $16,59^{\mathrm{bB}}$ & $17,19^{\mathrm{bAB}}$ & $17,60^{\mathrm{bAB}}$ & $17,23^{\mathrm{bAB}}$ & $17,25^{\mathrm{bAB}}$ & $17,36^{\mathrm{b}}$ \\
\hline SGMSU & $24,11^{\mathrm{aA}}$ & $22,09^{\mathrm{aB}}$ & $23,25^{\mathrm{aAB}}$ & $23,37^{\mathrm{aAB}}$ & $23,53^{\mathrm{aA}}$ & $22,85^{\mathrm{aAB}}$ & $23,20^{\mathrm{a}}$ \\
\hline \multicolumn{8}{|c|}{ Cinzas $(\%)$} \\
\hline SGMS & $2,43^{\mathrm{aAB}}$ & $2,32^{\mathrm{aB}}$ & $2,32^{\mathrm{aB}}$ & $2,38^{\mathrm{aAB}}$ & $2,34^{\mathrm{aB}}$ & $2,49^{\mathrm{aA}}$ & $2,38^{\mathrm{a}}$ \\
\hline SGMSI & $2,31^{\mathrm{bAB}}$ & $2,23^{\mathrm{abB}}$ & $2,24^{\mathrm{aB}}$ & $2,40^{\mathrm{aA}}$ & $2,29^{\mathrm{aAB}}$ & $2,38^{\mathrm{bA}}$ & $2,31^{\mathrm{b}}$ \\
\hline SGMSU & $2,41^{\mathrm{abA}}$ & $2,19^{\mathrm{bB}}$ & $2,32^{\mathrm{aA}}$ & $2,32^{\mathrm{aA}}$ & $2,34^{\mathrm{aA}}$ & $2,35^{\mathrm{bA}}$ & $2,32^{b}$ \\
\hline \multicolumn{8}{|c|}{$\mathrm{pH}$} \\
\hline SGMS & $4,02^{\mathrm{bA}}$ & $3,83^{\mathrm{bA}}$ & $4,02^{\mathrm{bA}}$ & $4,12^{\mathrm{bA}}$ & $4,22^{\mathrm{bA}}$ & $4,07^{\mathrm{bA}}$ & $4,05^{b}$ \\
\hline SGMSI & $4,02^{\mathrm{bA}}$ & $3,88^{\mathrm{bA}}$ & $4,04^{\mathrm{bA}}$ & $4,18^{\mathrm{bA}}$ & $4,24^{\mathrm{bA}}$ & $4,07^{\mathrm{bA}}$ & $4,07^{\mathrm{b}}$ \\
\hline SGMSU & $7,2^{\mathrm{aA}}$ & $7,54^{\mathrm{aA}}$ & $7,39^{\mathrm{aA}}$ & $7,39^{\mathrm{aA}}$ & $7,52^{\mathrm{aA}}$ & $7,59^{\mathrm{aA}}$ & $7,44^{\mathrm{a}}$ \\
\hline
\end{tabular}

Médias seguidas por diferentes letras minúsculas na coluna e maiúscula na linha diferem entre si, a 5\% de erro pelo teste Tukey.

SGMS = silagem de grãos úmidos de milho $+20 \%$ de soja crua; SGMSI $=$ silagem de grãos úmidos de milho $+20 \%$ de soja crua + inoculante microbiano; e SGMSU $=$ silagem de grãos úmidos de milho+ $20 \%$ de soja crua $+1,4 \%$ de ureia. 
A SGMSU apresentou maiores teores de FDN e de FDA na abertura dos silos, o que pode ser atribuído a ausência de hidrólise ácida, devido ao alto $\mathrm{pH}$ da silagem. De acordo com McDonald et al. (1991) diminuições dos teores de fibras podem ocorrer devido a uma hidrólise ácida parcial de hemicelulose devido a presença de ácidos produzidos durante a fermentação. Assim sendo, pode-se inferir que o fenômeno ocorreu nas silagens SGMS e SGMSI, reduzindo os teores de FDN em relação à SGMSU. Com o tempo de exposição ao ar nota-se que ocorreu concentração no teor de FDN para ambas as silagens, possivelmente devido à utilização de outros nutrientes pelos microrganismos. Verifica-se que com 96 horas de exposição ao ar a SGMS apresentou maior valor de cinzas, apresentando também a maior média total dos tempos de exposição ao ar. Segundo Ashbell (1995), a elevação no teor de cinza é um indicativo de perdas, pois, quando ocorre fermentações secundárias, ocorrem perdas de material orgânico, aumentando a participação relativa da material mineral na matéria seca.

Os teores de PB também tenderam a diminuir com o tempo de exposição ao ar para todos os tratamentos. Entretanto o teor de PB da silagem inoculada com L. buchneri foi maior que a verificada para a SGMS. De acordo com Kung et al. (2010) durante a fermentação o $L$. buchneri produz acido acético e 1,2 propanodiol da degradação de acido lático, e a Propionibactéria é capaz de converter acido lático e glicose para ácido acético e propiônico, que são compostos mais antifúngicos que ácido lático, podendo limitar ou inibir o crescimento de bactérias que degradam proteínas. Kung Junior et al. (2007), verificaram que a inoculação com níveis de L. buchneri aumentou a estabilidade aeróbia por aumentar as concentrações de acido acético da silagem de grãos úmidos de milho .

Houve efeito $(\mathrm{P}<0,05)$ da adição de uréia nos teores de $\mathrm{PB}$ das silagens. A uréia além de ser uma fonte de nitrogênio não protéico atua também na dinâmica fermentativa, alterando o $\mathrm{pH}$ e a pressão osmótica da massa de forragem. O elevado $\mathrm{pH}$ da SGMSU pode ser explicado pela hidrolise da uréia à amônia devido a enzima urease durante o processo de ensilagem, elevando a capacidade tampão do material ensilado (KUNG et al., 2003). Para as demais silagens o $\mathrm{pH}$ durante a exposição ao ar manteve-se entre valores de 4,02 - 4,24 valores próximos aos encontrados por Ítavo et al. (2006) \& Silva et al. (2010), para silagens de grãos $(4,22-4,14)$ o que estaria dentro da faixa ideal recomendada para silagem $(3,8$ a 4,2$)$.

Muck (2010), relata que silagens inoculadas com Lactobacillus buchneri podem apresentar $\mathrm{pH}$ mais alto em face da conversão do ácido lático em acético e propiônico e álcoois. Neste trabalho, porém, as silagens aditivadas com inoculante microbiano não mostraram diferença nos valores de $\mathrm{pH}$ em relação a SGMS. Não foi observada variação do $\mathrm{pH}$ durante o período total de exposição ao ar (96 horas) para as silagens estudadas, o que é um indício de uma boa estabilidade em aerobiose. De acordo com Wilkinson \& Davies (2012), silagens produzindo menos de $10 \mathrm{~g}$ de $\mathrm{CO}_{2}$ por $\mathrm{kg}$ de matéria seca, e que apresentam mudanças no $\mathrm{pH}$ menor que 0,5 unidades em um período de 5 dias de exposição ao ar, são consideradas estáveis.

Durante o período de exposição ao ar, o $\mathrm{pH}$ e a EB não mostraram-se como bons indicadores de estabilidade aeróbia, visto que não apresentaram comportamento definido. Entretanto, a deterioração da silagem foi mais visível 
nos teores da FDN que concentrou-se com o passar do tempo de exposição ao oxigênio, evidenciando perdas de componentes não estruturais .

A perda de matéria seca total no período de exposição ao ar foi semelhante entre as silagens, com valores de 4,39; 3,55 e 3,32\% para SGMSU; SGMS e SGMSI respectivamente. Observa-se que estas, seguiram o mesmo comportamento entre as silagens, com maiores perdas no tempo de 48 horas de exposição ao ar (Tabela 4). Se o período de exposição ao ar for longo podem ocorrer grandes alterações na composição química das silagens, o que influi prejudicialmente em seu valor nutritivo. Incialmente os componentes solúveis das silagens e os ácidos orgânicos servem como substratos para o desenvolvimento de fungos e leveduras, podendo também utilizar constituintes da parede celular como substrato (McDONALD et al., 1991).

Tabela 4. Perdas de matéria seca das silagens de grãos úmidos de milho nos diferentes tempos de exposição ao ar

\begin{tabular}{lllllll}
\hline Item & $8 \mathrm{~h}$ & $24 \mathrm{~h}$ & $48 \mathrm{~h}$ & $72 \mathrm{~h}$ & $96 \mathrm{~h}$ & Total \\
\hline SGMS & $0,21^{\mathrm{aB}}$ & $0,99^{\mathrm{aA}}$ & $1,06^{\mathrm{aA}}$ & $0,82^{\mathrm{aA}}$ & $0,40^{\mathrm{aB}}$ & $3,55^{\mathrm{a}}$ \\
SGMSI & $0,21^{\mathrm{aB}}$ & $0,88^{\mathrm{aA}}$ & $1,02^{\mathrm{aA}}$ & $0,76^{\mathrm{aA}}$ & $0,33^{\mathrm{a}} \mathrm{B}$ & $3,32^{\mathrm{a}}$ \\
SGMSU & $0,39^{\mathrm{aB}}$ & $1,11^{\mathrm{aA}}$ & $1,11^{\mathrm{aA}}$ & $0,87^{\mathrm{aA}}$ & $0,42^{\mathrm{aB}}$ & $4,39^{\mathrm{a}}$ \\
\hline
\end{tabular}

Médias seguidas por diferentes letras minúsculas na coluna e maiúscula na linha diferem entre si, a 5\% de erro pelo teste Tukey.

SGMS $=$ silagem de grãos úmidos de milho $+20 \%$ de soja crua; SGMSI $=$ silagem de grãos úmidos de milho $+20 \%$ de soja crua + inoculante microbiano; e SGMSU $=$ silagem de grãos úmidos de milho+ $20 \%$ de soja crua $+1,4 \%$ de ureia.

Entretanto, observa-se de uma forma geral que as silagens apresentaram boa estabilidade no período de 96 horas, com poucas perdas de MS e sem variação consistente na composição química, o que pode ser devido à adequada conservação do material ou ainda as condições do ambiente no momento de abertura dos silos, com baixas temperaturas, pouco favoráveis ao desenvolvimento de microrganismos deterioradores da silagem.

A temperatura e o tempo de exposição têm um efeito significativo sobre a deterioração aeróbia da silagem, sendo que temperaturas ambientais acima de $30^{\circ} \mathrm{C}$ favorecem o desenvolvimento de microrganismos indesejáveis (KOC et al., 2009). Nesse contexto, Ashbell et al. (2002) avaliaram a estabilidade aeróbia de silagens de trigo e de milho em diferentes temperaturas ambientais 10 ; $20 ; 30$ e $40^{\circ} \mathrm{C}$ e verificaram que amostras incubadas a $30{ }^{\circ} \mathrm{C}$ tiveram as maiores populações de leveduras, a maior produção de $\mathrm{CO}_{2}$ e maiores aumentos no $\mathrm{pH}$. As silagens expostas a 10 ou $40^{\circ} \mathrm{C}$ mantiveram-se estáveis.

$\mathrm{O}$ desaparecimento ruminal da matéria seca em 24 horas de incubação foi semelhante entre as silagens (Figura 2), com desaparecimento de 93,8; 92,7 e $86 \%$ para as silagens SGMS, SGMSI e SGMSU respectivamente. Os dados observados estão coerentes com os resultados normalmente observados para silagens de grãos de milho (JOBIM et al., 2008) .

O desaparecimento da proteína bruta (Figura 3) em 24 horas apresentou valores de 96,$1 ; 95,3$ e $90,8 \%$ para as silagens SGMS, SGMSI e SGMSU 
respectivamente. A silagem tratada com uréia mostrou desaparecimento mais lento da matéria seca e da proteína bruta em comparação as outras silagens avaliadas. Resultados semelhantes foram obtidos por Srivastava \& Mowat (1980), que verificaram que com o aumento do nível de amônia na silagem de milho houve uma diminuição na taxa de desaparecimento do amido, possivelmente devido a amônia reagir quimicamente com lipídios poliinsaturados e com açúcares na reação de Maillard, que tem efeito visível no escurecimento da silagem.

Houve uma tendência a um menor desaparecimento ruminal da MS em 24 $\mathrm{h}$ para a silagem tratada com inoculante microbiano, constatando-se que esta silagem apresentou um maior teor proteico que a SGUMS. De acordo com Hoffman \& Shaver (2011) o teor de proteínas está negativamente relacionado à digestão do amido, visto que proteínas prolaminas-zeínas são responsáveis por encapsular amido reduzindo assim sua digestibilidade. Entretanto, com um tempo maior de incubação (48 horas) nas análises de digestibilidade in vitro não foi verificada diferença $(\mathrm{P}>0,5)$ entre as silagens avaliadas, com valores de DIVMS de $96 \%$ para SGMS, SGMSI e SGMSU. Diaz et al. (2013) também não verificaram diferenças para digestibilidade de bovinos alimentados com silagem de grãos úmidos com a utilização de bactérias homo ou heterolaticas ou utilização de amonia.

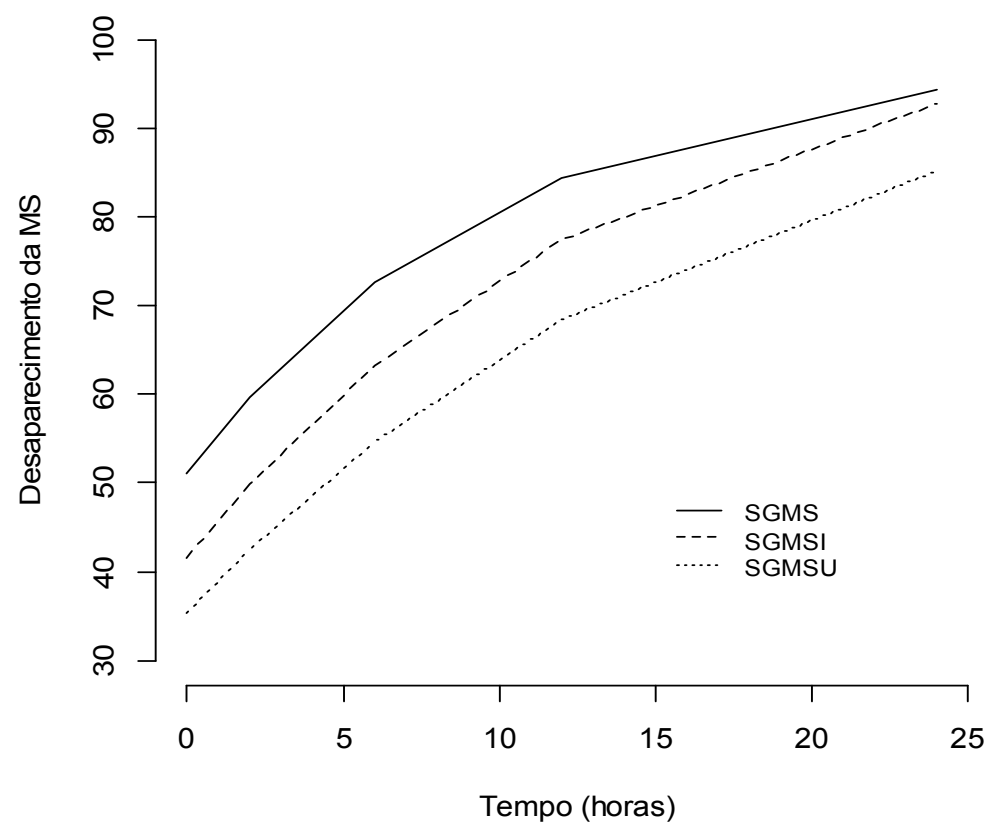

Figura 2. Curvas de desaparecimento ruminal da matéria seca ajustadas, respectivamente, para silagem de grãos úmidos de milho $+20 \%$ de soja crua (SGMS); silagem de grãos úmidos de milho $+20 \%$ de soja crua + inoculante microbiano (SGMSI) e silagem de grãos úmidos de milho $+20 \%$ de soja crua $+1,4 \%$ de uréia (SGMSU) 


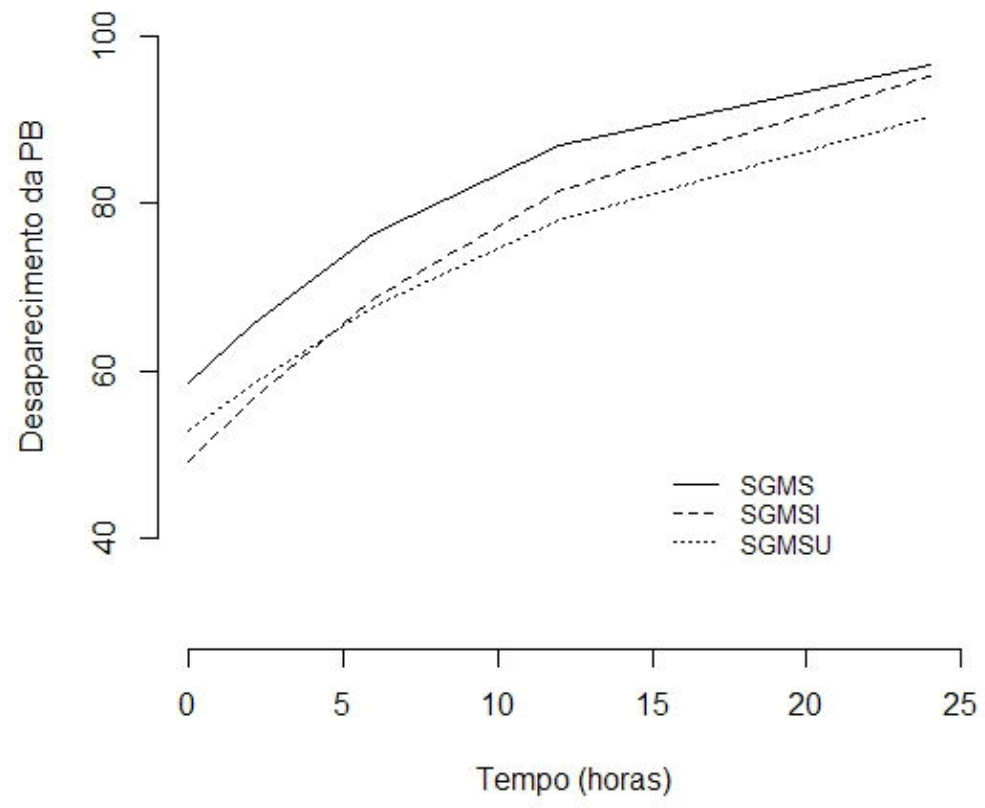

Figura 3. Curvas de desaparecimento da Proteína Bruta ajustadas, respectivamente, para silagem de grãos úmidos de milho $+20 \%$ de soja crua (SGMS); silagem de grãos úmidos de milho $+20 \%$ de soja crua + inoculante microbiano (SGMSI) e silagem de grãos úmidos de milho $+20 \%$ de soja crua $+1,4 \%$ de uréia (SGMSU)

Não houve diferença $(\mathrm{P}>0,05)$ para a composição química e produção de leite em função do concentrado utilizado, evidenciando o potencial do uso de concentrados formulados com base de silagem de grãos de milho enriquecido com grãos de soja no momento da ensilagem (Tabela 5). Esse procedimento visa facilitar a formulação e os procedimentos de misturas dos ingredientes na propriedade. A composição media do leite em relação à gordura e proteína foi de 3,66 e 3,27\%, respectivamente. Os teores médios de lactose $(4,53 \%)$ e sólidos totais $(12,43 \%)$ estão dentro dos valores normalmente observados para o leite de vacas (PANICHI et al., 2012; PYSERA et al., 2012; GARCIA et al., 2010).

Tabela 5. Composição química do leite de vacas da raça Holandesa alimentadas com concentrado comercial (Conc 1) ou concentrado a base de silagem de grãos de milho (Conc 2), média de quatro avaliações

\begin{tabular}{cccccc}
\hline Tratamentos & Gordura (\%) & Proteína (\%) & Lactose (\%) & Sólidos Totais (\%) & $\begin{array}{c}\text { Prod. Leite } \\
(\mathrm{kg} / \mathrm{vaca})\end{array}$ \\
\hline Conc 1 & 3,74 & 3,23 & 4,58 & 12,52 & 20,78 \\
Conc 2 & 3,58 & 3,31 & 4,49 & 12,34 & 21,45 \\
\hline CV (\%) & 8,24 & 9,54 & 7,71 & 8,39 & 12,45 \\
\hline
\end{tabular}

Conc. 1 = silagem de grãos de milho $+20 \%$ de soja crua, Conc. $2=$ concentrado comercial. 
A produção de leite, dos animais que receberam o concentrado a base de silagem de grãos de milho + soja, foi $3,2 \% \quad(0,670 \mathrm{~L} / \mathrm{vaca} / \mathrm{dia})$ maior em relação ao tratamento controle, o que pode ser atribuído ao maior aproveitamento dos grãos de milho ensilados em relação aos grãos seco (BENTON et al., 2005). Embora não houve efeito estatístico $(\mathrm{P}>0,05), \quad \mathrm{o}$ resultado pode ser analisado pelo ponto de vista de melhor resposta em relação à produção por lactação. De acordo com Panichi et al. (2012) a silagem de grãos úmidos de milho quando comparada com o grão seco mostrou mais eficiente e proporcionou melhor aproveitamento dos nutrientes da dieta total de vacas leiteiras.

Assim, para estas condições experimentais constatou-se que as silagens apresentaram-se estáveis no período de 96 horas, com reduzidas perdas de MS. A energia bruta não mostrou ser uma variável adequada para estimativas de perdas da qualidade das silagens durante a exposição aeróbia.

A adição de uréia diminuiu a taxa de degradação ruminal das silagens de grãos úmidos de milho com adição de soja.

A formulação de concentrado a base de silagem de grãos de milho com adição de soja crua para vacas em lactação não alterou a produção e composição química do leite.

\section{REFERÊNCIAS}

ASHBELL, G. Basic principles of preservation of forage, by-products and residues as silage or hay. Bet Dagan: Agricultural Research Organization, The Volcani Center, 1995. 58p.
ASHBELL, G.; WEINBERG, Z.G.; HEN, Y.; FILYA, I. The effects of temperature on the aerobic stability of wheat and corn silages. Journal of Industrial Microbiology \& Biotechnology, v28, p.261-263, 2002.

BENTON, J.R.; KLOPFENSTEIN, T.J.; ERICKSON, G.E. Effects of corn moisture and length of ensiling on dry matter digestibility and rumen degradable protein. Lincoln: University of Nebraska/Nebraska Beef Cattle Reports, 2005. p.31-33.

BORREANI, G.; TABACCO, E. The relationship of silage temperature with the microbiological status of the face of corn silage bunkers. Journal of Dairy Science, v.93, p.2620-2629, 2010.

CHELI, F.; CAMPAGNOLI, A.; ORTO, V.D. Fungal populations and micotoxins in silages: From occurence to analysis. Animal Feed Science and Technology, v.183, p.1-16, 2013.

CHERNEY, J.H.; CHERNEY, D.J.R. Assessing Silage Quality. In: BUXTOU, D.R.; MUCK, R.E.; HARISSON, J.H. (Eds.). Silage

Science and Technology. Madison, Wisconsin: University of Wisconsin, 2003. p.141-198.

DIAZ, E.; OUELLET, D.R.; AMYOT, A.; BERTHIAUME, R.; THIVIERGE, M.C. Effect of inoculated or ammoniated high-moisture ear corn on finishing performance of steers. Animal Feed Science and Technology, v.182, p.25-32, 2013.

GARCIA, G.A.G.; REIS, R.B.; PEREIRA, A.B.D.; SATURNINO, H.M.; COELHO, S.G. Milk production and composition of dairy cows grazing elephantgrass (Pennisetum purpureum) supplemented with different sources of 
Rev. Bras. Saúde Prod. Anim., Salvador, v.15, n.1, p.248-260 jan./mar., 2014 http://www.rbspa.ufba.br ISSN 15199940

carbohydrates. Arquivo Brasileiro de Medicina Veterinária e Zootecnia, v.62, n.4, p.875-882, 2010.

HOFFMAN, P.C.; SHAVER, R.D. Grain quality: A dairy cow's perspective. In: WISCONSIN CROP MANAGEMENT CONFERENCE, 2011, Madison, Wisconsin.

Proceedings... Madison, Wisconsin: University of Wisconsin-Extension, 2011. p.51-73.

HOLDEN, L.A. Composition of methods of in vitro dry matter digestibility for than feeds. Journal of Dairy Science, v.82, n.8, p.1791-1794, 1999.

ÍTAVO, C.C.B.F.; MORAIS, M.G.; ÍTAVO, L.C.V.; SOUZA, A.R.D.L.; DAVY, F.C.A.; ALBERTINI, T.Z.; COSTA, C.; LEMPP, B.; JOBIM, C.C. Effect of microbial inoculation on the fermentative parameters and chemical composition of high moisture corn and sorghum grain silages. Revista

Brasileira de Zootecnia, v.35, n.3, p.655-664, 2006.

JOBIM, C.C.; BRANCO, A.F.; GAI, V.F.; CALIXTO JUNIOR, M.; SANTOS, G.T. Quality of high moisture corn grain silage with addition of raw soybean grains and parameters of partial and total digestibility in cattle.

Arquivo Brasileiro de Medicina Veterinaria e Zootecnia, v.62, n.1, p.107-115, 2010a.

JOBIM, C.C.; CALIXTO JUNIOR, M.; BUMBIERIS JUNOR, V.H.; OLIVEIRA, F.C.L. Chemical composition and quality of conservation of corn (Zea mays L.) grain silages with differents levels of soy grains (Glycine max Merril) Semina: Ciências Agrárias, v.31, n.3, p.773-782, 2010b.
JOBIM, C.C.; LOMBARDI, L.; MACEDO, F.A.F.; BRANCO, A.F. Quality of corn grain silage added with soybean, sunflower or urea. Pesquisa Agropecuária Brasileira, v.43, n.5, p.649-656, 2008.

JOBIM, C.C.; NUSSIO, L.G.; REIS, R.A.; SCHMIDT, P. Methodological advances in evaluation of preserved forage quality. Revista Brasileira de Zootecnia, v.36, p.101-119, 2007.

KOC, F.; COSKUNTUNA, L.; OZDUVEN, M.L.; COSKUNTUNA, A.; SAMLI, H.E. The effects of temperature on the silage microbiology and aerobic stability of corn and vetchgrain silages. Acta Agricultura e Scandinavica, v.59, p.239-246, 2009.

KUNG JUNIOR, L. Aerobic Stability of Silage. In: ALFALDA \& FORAGE SYMPOSIUM AND CORN/CEREAL SILAGE CONFERENCE, 2010, California. Proceedings... Davis: Plant Sciences Department, University of California, 2010.

KUNG JR, L; RANJIT, N.K. The effect of Lactobacillus buchneri and other additives on the fermentation and aerobic stability of barley silage. Journal of Dairy Science, v.84, p.1149-1155, 2001.

KUNG JUNIOR, L.; SCHMIDT, R.J.; EBLING, E.; HU, W. The effect of Lactobacillus buchneri 40788 on the fermentation and aerobic stability of ground and whole high moisture corn. Journal of Dairy Science, v.90, p.2309-2314, 2007.

KUNG JUNIOR, L.; STOKES, M.R.; LIN, C.J. Silage additives. In: BUXTON, D.R.; MUCK, R.E.; HARRISON, J.H. (Eds.) Silage science 
Rev. Bras. Saúde Prod. Anim., Salvador, v.15, n.1, p.248-260 jan./mar., 2014 http://www.rbspa.ufba.br ISSN 15199940

and technology. Wisconsin:

ASA/CSSA/SSSA, 2003. p.305-360.

McDONALD, P.; HENDERSON, A.R.; HERON, S.J.E. Biochemistry of silage. 2.ed. Marlow: Chalcombe Publication, 1991. 340p.

MUCK, R.E. Silage microbiology and its control through additives. Revista Brasileira de Zootecnia, v.39, p.183191, 2010.

PANICHI, A.; COSTA, C.; ALMEIDA JUNIOR, G.A.; MEIRELLES, P.R.L.; SILVA, M.G.B.; SILVEIRA, J.P.F. Substitution of dry shelled corn by the high moisture corn silage for lactating holstein cows. Archives of Veterinary Science, v.17, n.4, p.83-92, 2012.

PYSERA, B.; PURWIN, C.; LIPINSKI, K.; ANTOSZKIEWICZ, Z.;

SEDEREVICIUS, A.; TRAIDARAITE, A.; WYZLIC, I. Performance and composition of fatty acids in milk of cows feed diets with high moisture corno $\mathrm{r}$ corn cob mix. Veterinarija ir Zootechnika, v.80, p.70-76, 2012.

STATISTICAL ANALYSIS SYSTEM. SAS/STAT user's guide: statistics. Version 6. 4.ed. North Caroline, 1993. v.2, $943 p$.

SILVA, D.J.; QUEIROZ, A.C. Análise de alimentos: métodos químicos e biológicos. 3.ed. Viçosa: Universidade Federal de Viçosa, 2006. 235p.
SILVA, M.S.; CARNAÚBA, J.P.; SILVA, I.O.; ANDRADE, E.G.T.; MIRANDA, E.C.; AMORIM, E.P.R. Influence of bacterial-enzymatic inoculant on microbiota and nutritional quality of humid maize grain silages. Ciência Animal Brasileira, v.11, n.1, p.62-72, 2010.

SRIVASTAVA, V.K.; MOWAT, D.N. Preservation and processing of whole high moisture shelled corn with ammonia. Canadian Journal of Animal Science, v.60, p.683-688, 1980.

Van SOEST, P.J.; ROBERTSON, J.B. Analysis of forages and fibrous foods. Ithaca: Cornell University, 1985. 202p.

VANZANT, E.S.; COCHRAN, R.C; TITGEMEYER, E.C. Standardization of in situ techniques for ruminant feedstuff evaluation. Journal of Animal Science, v.76, p.2717-2729, 1998.

WILKINSON, J.M.; DAVIES, D.R. The aerobic stability of silage: Key findings and recent developments. Grass and Forage Science, v.68, p.119, 2012.

Data de recebimento: 12/09/2013

Data de aprovação: 28/03/2014 